\title{
NEUTRONICS ANALYSIS OF VVER-1000 CORE USING AT-FCM FUEL
}

\author{
Mahmood Ahmad Ghazanfar ${ }^{1 *}$, Wang $\operatorname{Kan}^{1}$ \\ ${ }^{1}$ Tsinghua University \\ Department of Engineering Physics, New LiuQing Building, Haidian District, Beijing P.R. \\ CHINA
}

jiangf16@mails.tsinghua.edu.cn, wangkan@mail.tsinghua.edu.cn

\begin{abstract}
Using the Fully Ceramic Microencapsulated (FCM) fuel in light water reactors has multiple advantages, as it is accident tolerant because of; no hydrogen generation due to the cladding interaction with steam at high temperature, better retention of fission fragments and proliferation resistant due to very small production of transuranic elements during the burnup as compared to the standard UO2 fuel. In this study neutronics analysis of AT-FCM fuel consisting of TRISO particles embedded in SiC matrix is performed for replacement in existing VVER-1000 reactors. Standard VVER-1000 fuel assembly is transformed to Accident Tolerant Fully Ceramic Microencapsulated (AT-FCM) fuel assembly based on hydraulic diameter of the VVER-1000 assembly, the number of fuel pins are decreased with increased diameter and enrichment to conserve the initial fissile loading in AT-FCM assembly. Fuel centerline temperature of the AT-FCM assembly is found to be lower than the reference UO2 fuel assembly at the same total power produced because of the much higher thermal conductivity. FCM-TRISO fuel assembly namely Array 15 with 169 pins is proposed and analyzed. Pin cell, assembly level and full core calculations have been performed with SERPENT code using implicit and explicit models. VVER-1000 full core is modelled using the transformed FCM assembly. The embedded TRISO particles in a SiC matrix and the use of FeCrAl cladding turns out to be the perfect case for accident tolerance. High burnup of ATFCM core in terms of MWd/kgHM for the same number of EFPDs is observed as compared to reference UO2 core due to the small breeding of transuranic elements $\mathrm{Pu}-239, \mathrm{Pu}-240$ and $\mathrm{Pu}-241$. Appreciable quantity of the power is produced due to the fission of transuranic elements in reference $\mathrm{UO}_{2}$ assembly so the burnup in $\mathrm{MWd} / \mathrm{kgHM}$ remains smaller than the AT-FCM fuel. Comparatively more softening of spectrum is found in AT-FCM fuel cells and assemblies towards the middle of the cycle (MOC) and End of the Cycle (EOC), this softening of spectrum tends to increase the rate of U-235 depletion. Very small quantities of plutonium isotopes are produced in AT-FCM as compared to the reference $\mathrm{UO}_{2}$ assembly because of small loading of U-238 at the BOC. The neutronics performance of AT-FCM core with burnable poison consisting of $\mathrm{Gd}_{2} \mathrm{O}_{3}$ and $\mathrm{Er}_{2} \mathrm{O}_{3}$ turn out to be better than reference $\mathrm{UO}_{2}$ assembly as it exhibits smooth burnup. Fuel Temperature Coefficient (FTC) and Moderator Temperature Coefficient (MTC) of the AT-FCM assembly is negative for most part of the cycle however, towards the end of cycle it becomes less negative due to small quantities of resonance absorbers, softening of thermal flux and increased rate of fission absorption in $\mathrm{UO}_{2}$.
\end{abstract}

KEYWORDS: Fully Ceramic Microencapsulated (FCM) fuel; SERPENT; TRISO particles, VVER-1000; 


\section{INTRODUCTION}

The idea of using FCM-TRISO fuel in LWRs is under consideration since the severe accident of Fukushima Daiichi power plants because of its proven performance in High Temperature Gas Cooled Reactors (HTGRs). It has multiple advantages such as better fission fragments retention, accident tolerant due to the use of innovative claddings, which does not interact with steam at high temperatures and proliferation resistance because of very small production transuranic elements. Research and development work is in progress to study the possible use of TRISO fuel in PWR environment [1] but almost no research work has been done on this fuel to be used in VVER type reactors. Many options are available for fuel kernel of the TRISO particles but lately most of the research work has been focused on Uranium Carbide (UC) and Uranium Nitride (UN). Similarly relatively new cladding concepts such as ferritic steel FeCrAl, Silicon Carbide SiC and alloys of zirconium have been studied; each one has its own advantages and disadvantages [2]. This neutronics analysis is performed using SERPENT code with explicit and implicit methods. Depletion analysis, energy spectrum analysis, transuranic elements breeding and reactivity coefficients of temperature are simulated considering the double heterogeneity of FCM-TRISO fuel.

The section two of this paper is about the Methods and materials while in section three the results of simulations have been discussed in detail. The conclusion of the results and future work is presented in section four.

\section{METHOD AND MATERIALS}

The standard assembly of VVER-1000 reactor, containing 331 pins in hexagonal geometry is taken as a reference assembly for this neutronics analysis. Reference assembly is transformed into accident tolerant Fully Ceramic Microencapsulated fuel (FCM-TRISO) assembly in two aspects i.e geometric transformation and enrichment transformation. The basic requirement of fuel centerline temperature in FCM assembly is also a constraint for this transformation. An assembly with 169 pins and FCM-TRISO fuel is proposed for assembly level calculations and then core design for VVER-1000 reactor. Fuel pin diameter of the FCM assembly is increased considering the much higher thermal conductivity of TRISO fuel embedded in SiC matrix [3]. The detailed transformation of reference assembly to FCM assembly is discussed in detail in the following section 2.2. These transformed FCM assemblies are then used to design VVER-1000 core and neutronics analysis is performed.

\subsection{Tools and Methodology}

Monte Carlo code SERPENT-1.1.19 [4] is used for this neutronics analysis. This code is capable of building complex combinatorial geometry and double heterogeneity of the TRISO fuel. The TRISO particles embedded in $\mathrm{SiC}$ are packed in fuel pin using implicit and explicit mehods. Burnup analysis of the FCMTRISO assembly is compared with the standard $\mathrm{UO}_{2}$ fuel assembly, spectrum analysis, relative power distribution, material inventories and burnup analysis with burnable absorbers has been performed in this study. ENDBF-VII.0 cross section libraries and periodic boundary conditions are applied in this analysis.

\subsection{Transformation of Reference $\mathrm{UO}_{2}$ Assembly to FCM Assembly}

A standard VVER-1000 assembly consists of 331 pins, among them 312 are fuel pins and 19 guide tubes for control assembly and instrumentation tube. The first step of the transformation is to calculate the fuel rod diameter and the pitch of fuel pins; this is determined by taking the pitch and hydraulic diameter of the reference assembly as constant. For FCM assembly 169 pins are fixed in hexagonal geometry, fuel rod diameter and other parameters of reference and FCM assemblies are presented in Table I. 
Table I. Description of the Assembly parameters.

\begin{tabular}{|l|c|c|}
\hline \multicolumn{1}{|c|}{ Parameters } & Reference Assembly & FCM Assembly \\
\hline Fuel pellet radius & $0.3917 \mathrm{~cm}$ & $0.6461 \mathrm{~cm}$ \\
\hline Fuel material/matrix & $\mathrm{UO}_{2}$ & $\mathrm{UC} / \mathrm{SiC}$ \\
\hline Packing fraction & - & $35 \%$ \\
\hline Enrichment & $4.2 \%$ & $15.97 \%$ \\
\hline Heavy metal loading/FA & $486.748 \mathrm{~kg}$ & $128.298 \mathrm{~kg}$ \\
\hline HM\% age of reference & $(100.0 \%)$ & $(26.35 \%)$ \\
\hline Initial fissile loading/FA & $20.43 \mathrm{~kg}$ & $20.43 \mathrm{~kg}$ \\
\hline Density of fuel & $10.40 \mathrm{~g} / \mathrm{cm}^{3}$ & $12.95 \mathrm{~g} / \mathrm{cm}^{3}$ \\
\hline Helium gap thickness & $0.0085 \mathrm{~cm}$ & $0.0085 \mathrm{~cm}$ \\
\hline Clad thickness & $0.069 \mathrm{~cm}$ & $0.057 \mathrm{~cm}$ \\
\hline No. of fuel rods & 312 & 160 \\
\hline Fuel rod radii (outer) & $0.4572 \mathrm{~cm}$ & $0.7116 \mathrm{~cm}$ \\
\hline No. of guide tubes & 19 & 9 \\
\hline Guide tube radii (outer/inner) & $0.630 \mathrm{~cm} / 0.550 \mathrm{~cm}$ & $0.8613 \mathrm{~cm} / / 0.8043 \mathrm{~cm}$ \\
\hline Helium density & $0.00222 \mathrm{~g} / \mathrm{cm}^{3}$ & $0.00222 \mathrm{~g} / \mathrm{cm}^{3}$ \\
\hline Density of clad material (FeCrAl) & - & $7.25 \mathrm{~g} / \mathrm{cm}^{3}$ \\
\hline Density of moderator $\left(\mathrm{H}_{2} \mathrm{O}\right)$ & $0.72701 \mathrm{~g} / \mathrm{cm}^{3}$ & $0.72701 \mathrm{~g} / \mathrm{cm}^{3}$ \\
\hline Fuel temperature (ave) & $990.0 \mathrm{~K}$ & $950.0 \mathrm{~K}$ \\
\hline Cladding temperature (ave) & $600.0 \mathrm{~K}$ & $600.0 \mathrm{~K}$ \\
\hline Moderator temperature (ave) & $574.0 \mathrm{~K}$ & $574.0 \mathrm{~K}$ \\
\hline Pin pitch & $1.275 \mathrm{~cm}$ & $1.785 \mathrm{~cm}^{3}$ \\
\hline Fuel assembly pitch & $21.55 \mathrm{~cm}$ & $21.55 \mathrm{~cm}$ \\
\hline Fuel assembly height & $353.0 \mathrm{~cm}$ & $353.0 \mathrm{~cm}$ \\
\hline Fuel assembly power & $18.6 \mathrm{MWt}$ & $18.6 \mathrm{MWt}$ \\
\hline
\end{tabular}

The second step of transformation is computation of required enrichment for FCM assembly, which should remain less than $20 \%$. A simple program presented in figure 1 is used for calculation of required enrichments and it is presented as a function of TRISO particle fuel kernel diameter and packing fraction. The reference assembly enrichment is $4.2 \mathrm{w} / \mathrm{o}$ and the corresponding enrichment for FCM assembly having $35 \%$ packing fraction [5] and 900-micrometer kernel diameter is $15.97 \mathrm{w} / \mathrm{o}$.

In the next step, fuel centerline temperature is determined using heat conduction equation [6] using conductive and convective boundary conditions and uniform power distribution. Parameters used for this computation are given in table II. The fuel centerline temperature presented in figure 2 in FCM assembly is much lower as compared to the reference assembly due to the very high thermal conductivity of TRISO fuel embedded in $\mathrm{SiC}$ matrix. There is a small difference in the average cladding temperature so it is taken same for both reference and FCM assemblies.

Table II. Heat transfer parameters.

\begin{tabular}{|l|c|c|c|}
\hline Assembly and Parameter & $\mathrm{q}^{\prime}(\mathrm{W} / \mathrm{m})$ & $\mathrm{K}(\mathrm{W} / \mathrm{m}-\mathrm{K})$ & $\mathrm{h}\left(\mathrm{W} / \mathrm{m}^{2}-\mathrm{K}\right)$ \\
\hline
\end{tabular}




\begin{tabular}{|l|l|c|l|}
\hline Reference pin & $1.66 \mathrm{E}+04$ & & \\
\hline FCM pin & $2.91 \mathrm{E}+04$ & & \\
\hline UO2 & & 3 & \\
\hline FCM fuel & & 13 & \\
\hline Helium Gas & & 0.31 & \\
\hline Zirlo ${ }^{\mathrm{TM}}$ & & 17 & \\
\hline FeCrAl & & 16 & \\
\hline Water & & & 20,000 \\
\hline
\end{tabular}

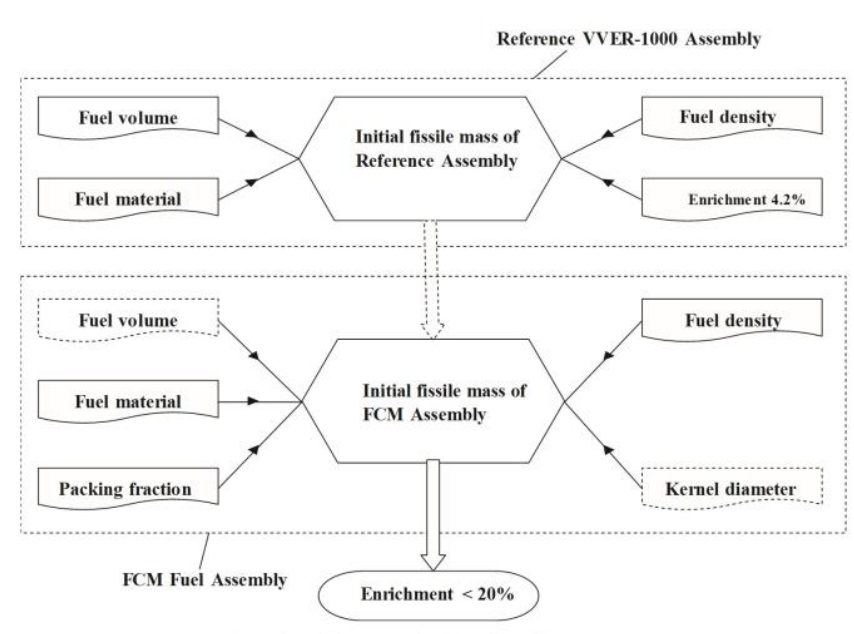

Flow Chart for determination of enrichment

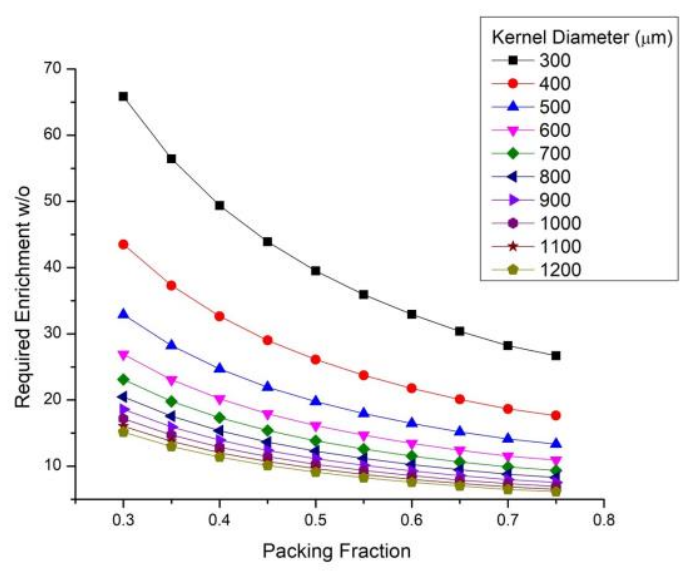

Enrichment requirement as a function kernel diameter

Figure 1. Enrichment determination.

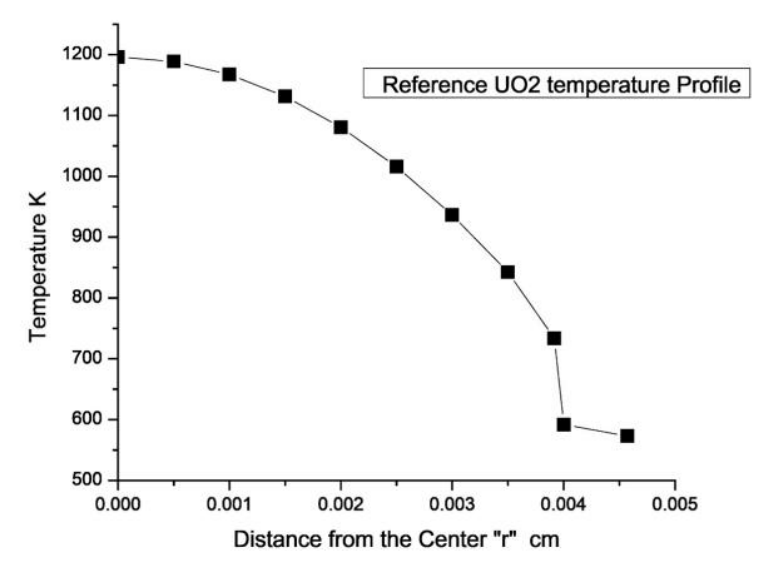

Reference Assembly

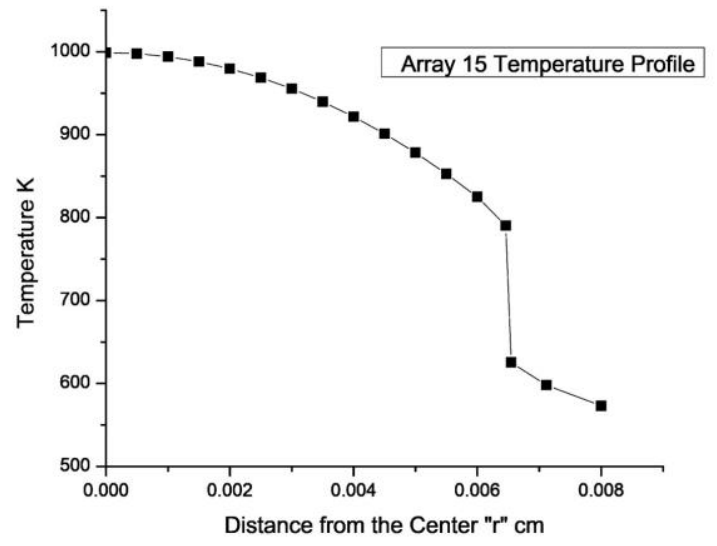

FCM Assembly

Figure 2. Fuel pin Temperature distribution of Reference and FCM assemblies.

\subsection{Optimization of FCM-TRISO Assembly}


The proposed FCM assembly is optimized for number and location of guide tubes and relative power distribution of fuel pins, nine guide tubes and their location is selected in such a way that maximum peaking factor of power shall not exceed 1.10. The reference assembly and optimized FCM fuel assembly is presented in figure 3 .

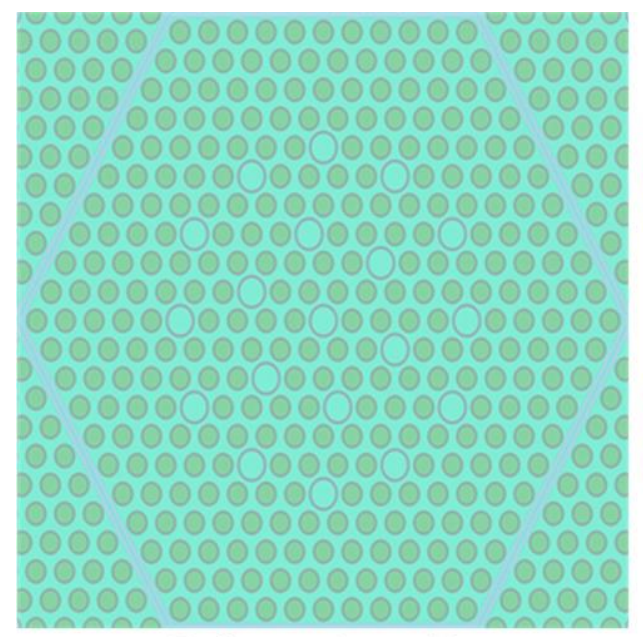

Reference Assembly

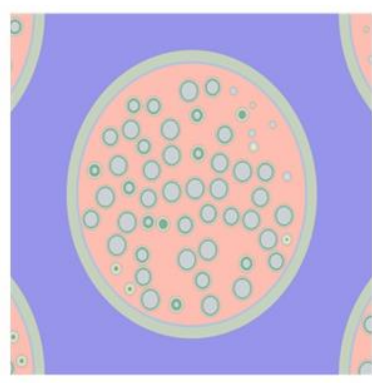

FCM Pin Cell

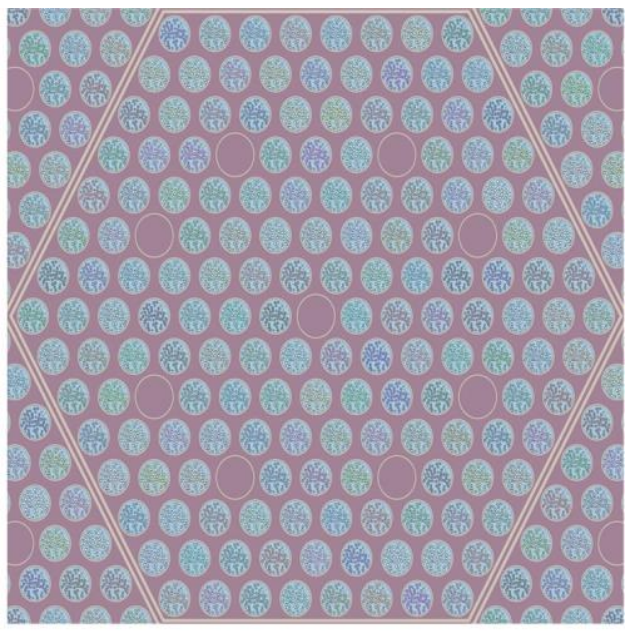

FCM Assembly

Figure 3. Geometry of Reference and FCM assemblies.

\subsection{Single Pin Criticality}

\section{RESULTS AND DISCUSSION}

For reference and FCM assemblies, single pin is modelled and criticality calculation is performed using implicit and explicit methods of particles packing in fuel pin. One hundred thousand particles with 500 active and 200 inactive cycles are used for this simulation and results of single pin infinite multiplication factors are presented in table III. The excess reactivity in the FCM pin is due to high enrichment and small loading of heavy metal.

Table III. Single pin infinite multiplication factor.

\begin{tabular}{|l|c|c|c|}
\hline \multicolumn{1}{|c|}{ Assembly } & K - infinity & $\begin{array}{c}\text { K- infinity } \\
\text { Implicit Model }\end{array}$ & $\begin{array}{c}\text { K- infinity } \\
\text { Explicit model }\end{array}$ \\
\hline Reference pin & 1.3750 & & \\
\hline FCM pin & & 1.5770 & 1.57812 \\
\hline
\end{tabular}

\subsection{Assembly Level Simulations}

\subsubsection{Burnup Analysis}

Depletion of reference assembly and FCM assembly is studied using the prescribed data in table I. High burnup of more than $100 \mathrm{MWd} / \mathrm{kgHM}$ in $\mathrm{FCM}$ assembly is observed compared to the typical 50 $\mathrm{MWd} / \mathrm{kgHM}$ of reference VVER-1000 assembly for the same number of EFPDs and Thermal Power (figure 4). The reason of much larger burnup of FCM assembly is small loading of heavy metal and small amount of transuranic elements i.e. $\mathrm{Pu}-239, \mathrm{Pu}-240$ and $\mathrm{Pu}-241$ production, which does not significantly contribute towards the fission rate and power generation as in the case of reference assembly. 

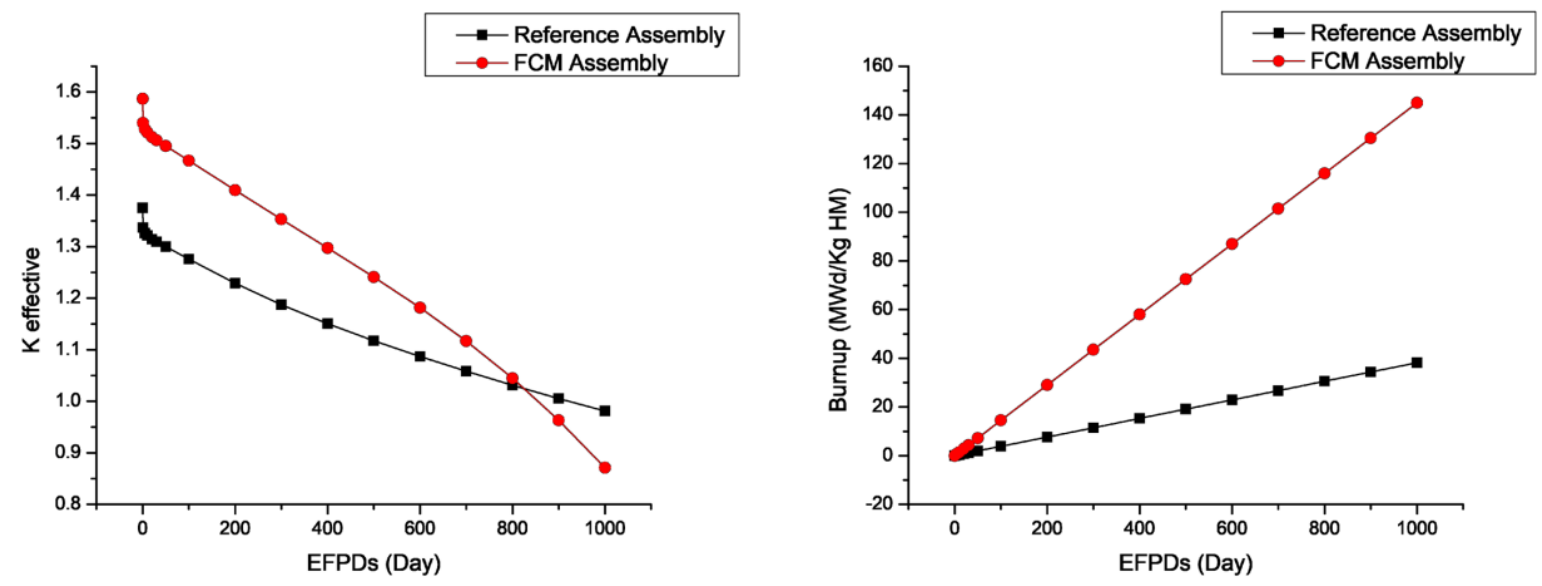

Figure 4. Burnup Analysis of Reference and FCM assemblies.

\subsubsection{Spectrum Analysis}

Energy spectrum of reference and FCM assembly, presented in figure 5 is simulated using 500 energy groups and without using soluble boron in the moderator. Excessive softening of the thermal flux in FCM assembly is attributed to the rapid rate of depletion of U-235 towards End of Cycle (EOC) and presence of carbon in the TRISO particles. The rapid rate of depletion of fissile material towards the EOC is the result of small production of transuranic elements in FCM assembly. Small production of transuranic elements leads to small contribution in fission rate and power generation as compared to reference $\mathrm{UO}_{2}$ assembly.

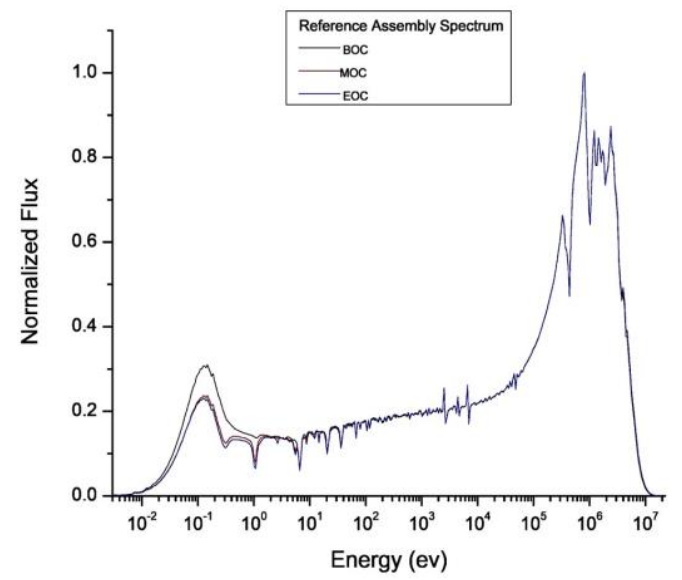

Reference Assembly

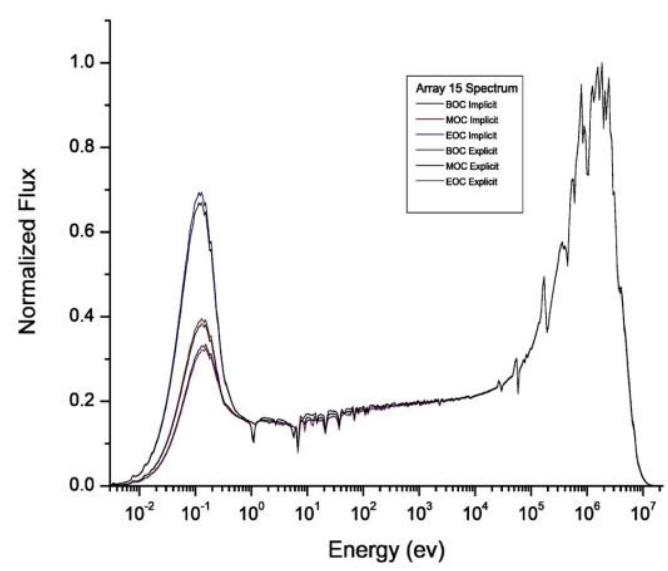

FCM Assembly

Figure 5. Spectrum Analysis of Reference and FCM assemblies.

\subsubsection{Material Inventories}

The production of transuranic elements $\mathrm{Pu}-239, \mathrm{Pu}-240$ and $\mathrm{Pu}-241$ in FCM assembly (figure 6) are smaller as compared to reference assembly because of smaller initial loading of U-238 in FCM assembly. Small production of transuranic elements in FCM assembly makes it proliferation resistant. Although the proliferation is more linked to the quality of plutonium in the spent fuel, the quantity of plutonium isotopes is also a parameter to determine the possibility of reprocessing. 


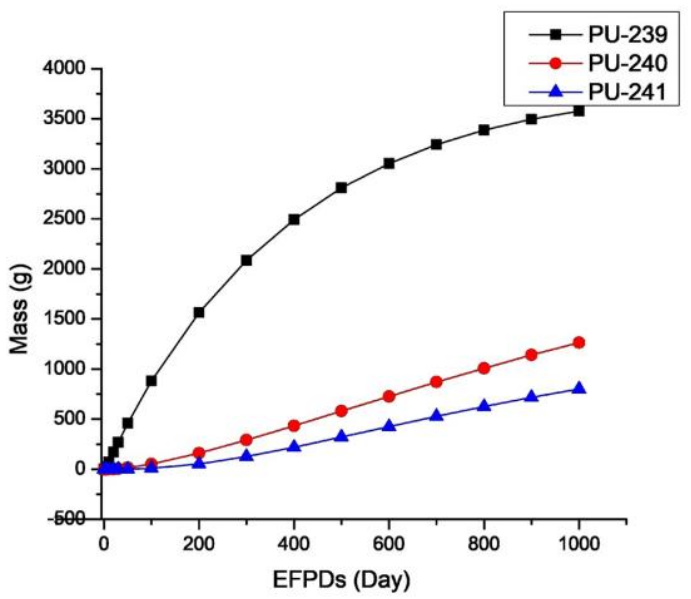

Reference Assembly

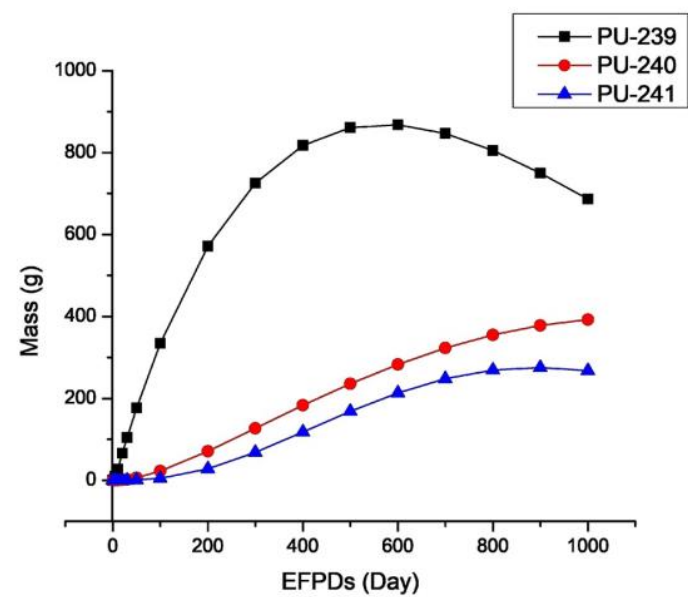

FCM Assembly

Figure 6. Material inventories of Reference and FCM assemblies.

\subsubsection{Burnup analysis with burnable absorbers}

The suppression of excess reactivity in FCM assembly can be done by the addition of burnable absorbers in the fuel. A layer of burnable poison is added above the fuel kernel in TRISO particle, which makes it QUADRISO particle. Two type of burnable absorbers $\mathrm{Gd}_{2} \mathrm{O}_{3}$ and $\mathrm{Er}_{2} \mathrm{O}_{3}$ have been used and the fuel assembly lattice is again optimized with 22 fuel pins of QUADRISO particles embedded in SiC matrix. The maximum peaking factor remains 1.08 in FCM assembly. The cross section of Gadolinium is lager than Erbium so Gd2O3 shows larger suppression of reactivity in the beginning of cycle (BOC) but the burnup with Er2O3 is smooth. At the end of cycle $\sim 2 \%$ and $\sim 5 \%$, mass of $\mathrm{Gd}$ and $\mathrm{Er}$ is left as residual respectively. Different layer thickness of burnable absorbers is used in QUADRISO particles and the burnup is presented in figure 7.
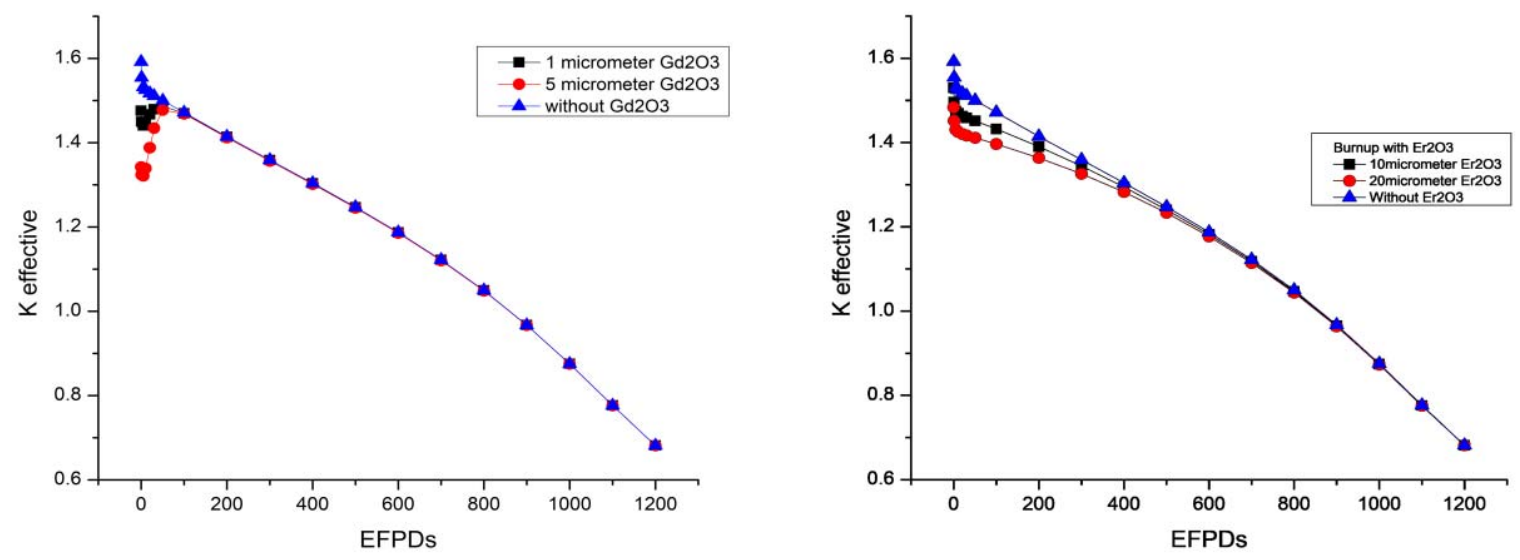

Figure 7. Burnup analysis with burnable absorbers.

\subsubsection{Temperature coefficients of reactivity}

Fuel temperature coefficient (FTC) and moderator temperature coefficient (MTC), presented in figure 8 are determined by simulating at variable fuel and moderator temperatures respectively. The FTC is calculated by changing the fuel temperature from $300 \mathrm{~K}$ to $1500 \mathrm{~K}$ and keeping all the conditions constant at cold zero 
power. Similarly, the MTC calculation is performed by changing the moderator temperature by 4K steps [7] and keeping the system temperature constant at inlet temperature. Both FTC and MTC are negative for full cycle but keep increasing to positive towards EOC; it is partly due to the excessive softening of the thermal spectrum towards EOC and partly due to presence of excessive carbon in the fuel. The negative trend of FTC and MTC remains same with soluble boron used in the moderator. The expected cycle length of FCM assembly based on negative temperature coefficients is $\sim 800$ EFPDs which is much larger than reference assembly.
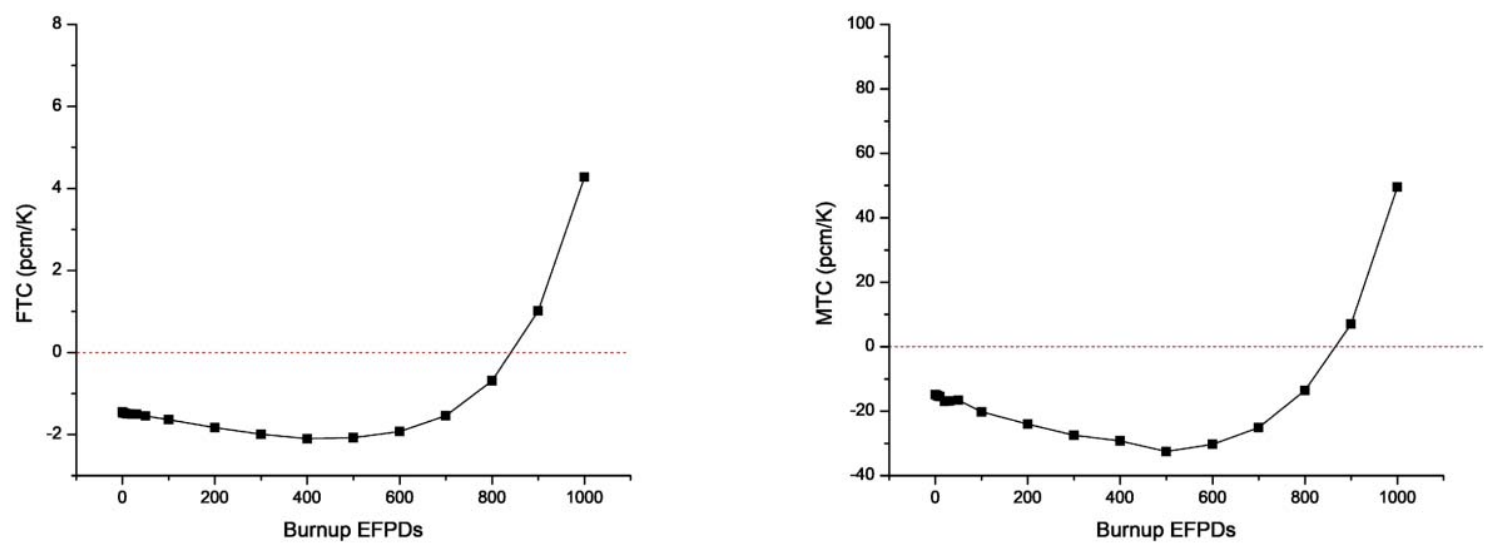

Figure 8. Temperature coefficients of reactivity.

\subsection{Full Core Simulations.}

VVER-1000 full core with 163 assemblies has been modelled using FCM assemblies as shown in figure 9. Two different problems with single enrichment and three enrichments are considered for burnup analysis. The corresponding enrichments of FCM assembly has been calculated based on the program explained in figure 1. Full core simulation data is provided in Appendix B.
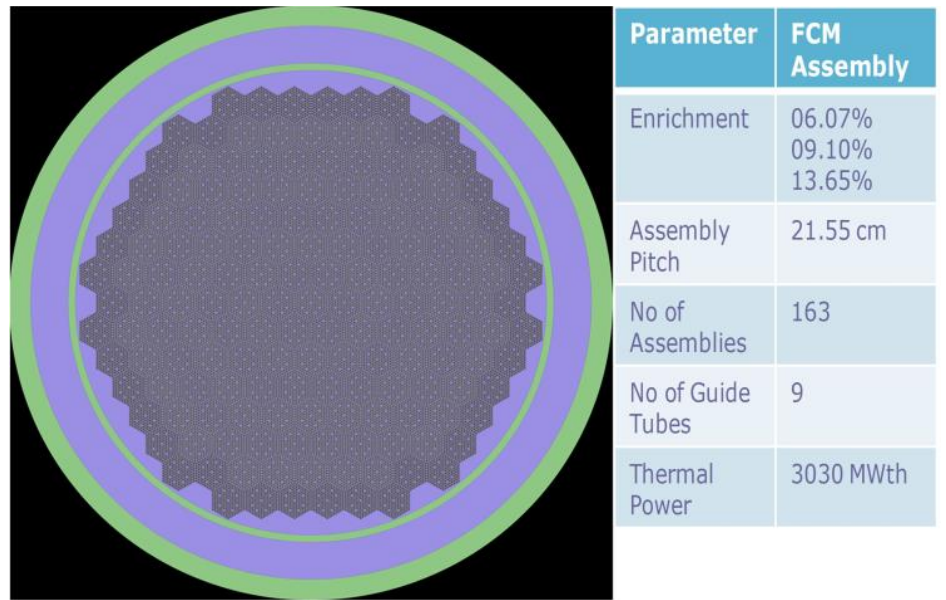

Figure 9. Full Core geometry with parameters.

\subsubsection{Full core burnup analysis.}

Full core consisting of FCM assemblies is simulated using $1 \mathrm{M}$ particles with 300 inactive and 1000 active cycles to reduce the statistical fluctuations and standard deviation. Figure 10 presents the full core burnup 
of three enrichment problem and single enrichment problem. Considerably small cycle length is predicted in three-enrichment core but a large cycle length of about 700 EFPDs is predicted in single enrichment core. Following calculations are based on the single enrichment core. The smooth burnup is observed using different concentrations of boron.

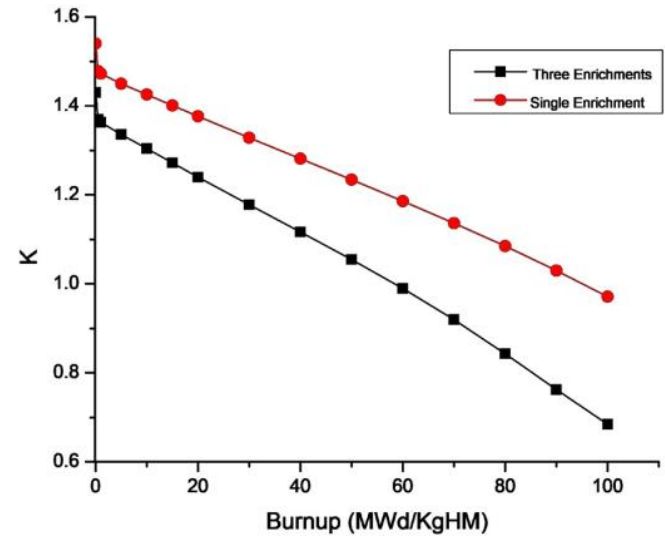

Core Burnup without Boron

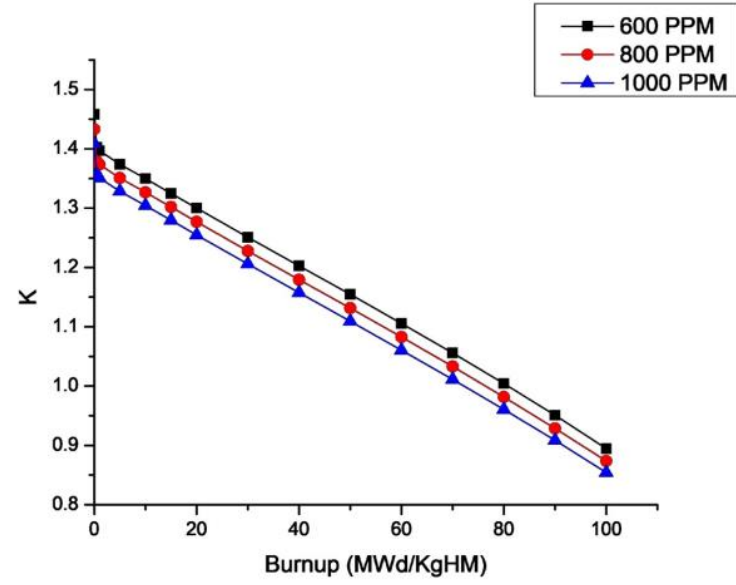

Single Enrichment Core Burnup with Boron

Figure 10. Full core burnup analysis.

\subsubsection{Full core burnup with burnable absorbers.}

The burnup of single enrichment full core is simulated using burnable absorbers and 800-ppm boron. The burnable absorber is used in the form of QUADRISO particles. FCM assembly has 22 optimized pins (as explained in section 3.2.4) for QUADRISO particles. The suppression of reactivity with $\mathrm{Gd}_{2} \mathrm{O}_{3}$ is large early on (figure 11) and with the decrease of Gadolinium isotope, the burnup becomes smooth. Only 2\% mass of the Gadolinium is left after the full cycle. Using 800-ppm boron in the moderator further decreases the reactivity and burnup behavior remains same.

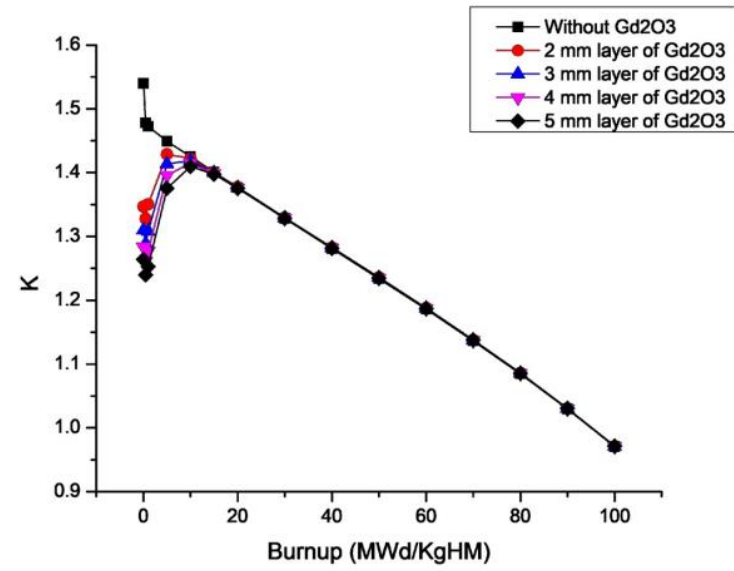

Without Boron

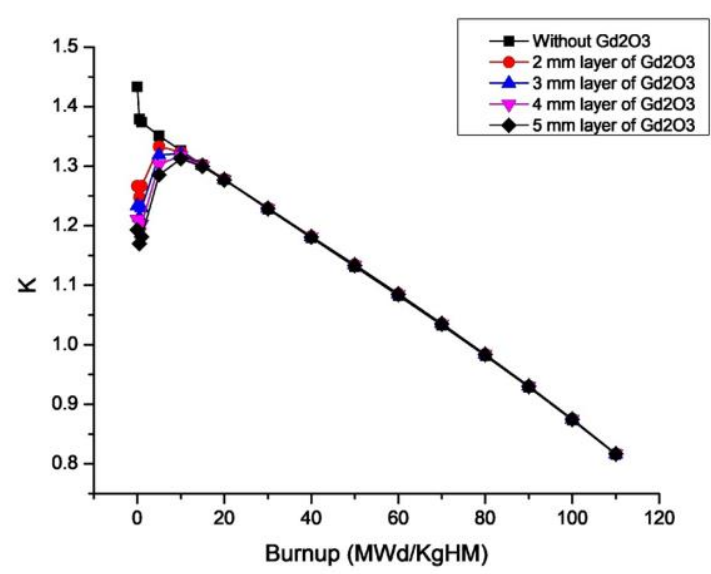

With 800 ppm Boron

Figure 11. Full core burnup with $\mathrm{Gd}_{2} \mathrm{O}_{3}$ as Burnable Absorber.

Another burnable absorber $\mathrm{Er}_{2} \mathrm{O}_{3}$ is simulated for full core burnup and the burnup behavior is found relatively smooth (figure 12) as compared to $\mathrm{Gd}_{2} \mathrm{O}_{3}$. Only $\sim 5 \%$ residual mass of Erbium is recorded after full cycle. Using 800-ppm soluble boron in the moderator further decreases the reactivity and burnup behavior remains same. 


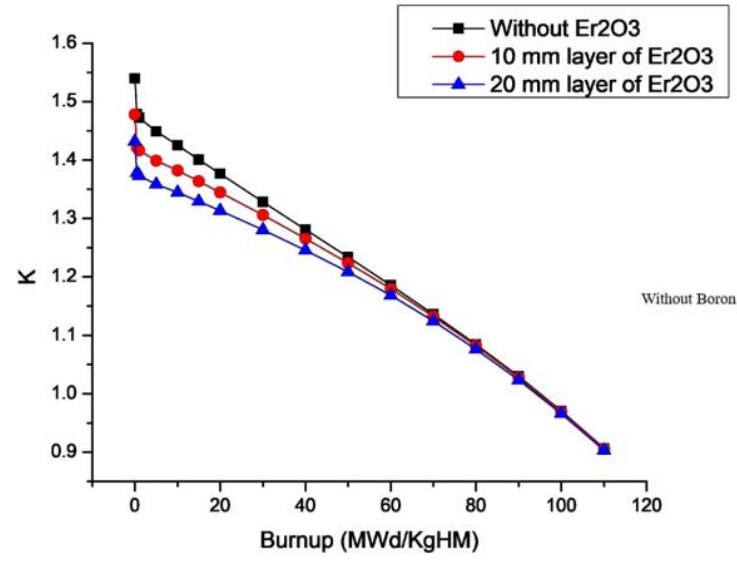

Without Boron

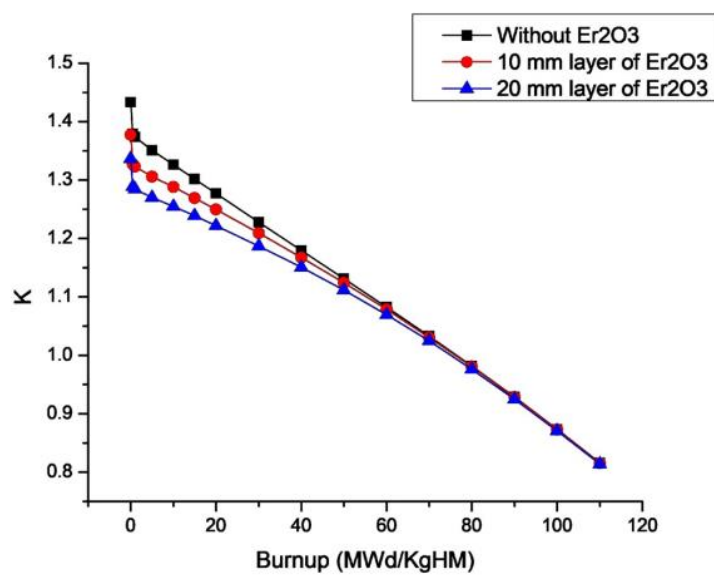

With 800 ppm Boron

Figure 12. Full core burnup with $\mathrm{Er}_{2} \mathrm{O}_{3}$ as Burnable Absorber.

\section{CONCLUSION AND FUTURE WORK}

The purpose of this study is to perform a preliminary neutronics analysis of FCM-TRISO fuel to be used in VVER-1000 reactor core. The conversion of standard reference assembly to FCM assembly is based on assumptions like hydraulic diameter same as reference assembly, same thermal power, and low enrichment limit i.e. less than $20 \%$. The detailed burnup analysis of FCM assembly and full core presents encouraging results. The temperature coefficients of reactivity FTC and MTC are negative for a longer cycle length. Another advantage of FCM fuel in VVER-1000 is very small production of transuranic elements, which makes it proliferation resistant. The innovative cladding concept of ferritic steel FeCrAl makes it accident tolerant because of no hydrogen production. Furthermore, in depth analysis of control assemblies and thermal hydraulics is required to assess the performance of FCM fuel in VVER-1000 reactor core.

\section{ACKNOWLEGEMENT}

The authors would like to acknowledge the support provided by China Scholarship Council via grant no 2016GXZD60. INESEM, Tsinghua University provided the necessary resources to carry out this work.

\section{REFERENCES}

1. Pope, Michael.A., Sonat Sen, R., Ougouage, Abderrafi.M., Touinou, Giles, Boer, Brian, 2012. Neutronic analysis of burning of transuranics in fully ceramic microencapsulated tri-isotropic particlefuel in a PWR. Nuclear Engineering and Design. 252, 215-225.

2. Kimura, K. et al., 2007. High burnup fuel cladding materials R\&D for advanced nuclear systems. Journal of Nuclear Science and Technology. 44 (3), 323-328.

3. Folsom, C., Xing, C., Jensen, C., Ben, H., Marshall, D.W., 2015. Experimental measurement and numerical modeling of the effective thermal conductivity of TRISO fuel compact. Journal of Nuclear Materials. 458, 198-205.

4. J. Lappänan, "Serpent - a Continuous-energy Monte Carlo reactor physics burnup calculation code", VTT Technical Research Center of Finland (2015).

5. Peter, J.P., Robert, N.M., 2007. Estimation of maximum-coated particle fuel fraction compact packing fraction. Journal of Nuclear Materials. 361 (1), 18-29.

6. Todreas, N.E., Kazimi, M.S.," Nuclear Systems I: Thermal Hydraulics Fundamentals", Taylor \& Francis, 2nd Printing, USA 1993.

7. Mourtazanos, K., Housiadas, C., Domis, M.A., 2001. Calculation of the moderator temperature coefficient of reactivity for water moderated reactor. Ann. Nucl. Environ. 28, 1773-1782. 


\section{APPENDIX A}

\section{Description of TRISO Particles}

TRISO and QUADRISO particle geometry is described in the following diagrams.
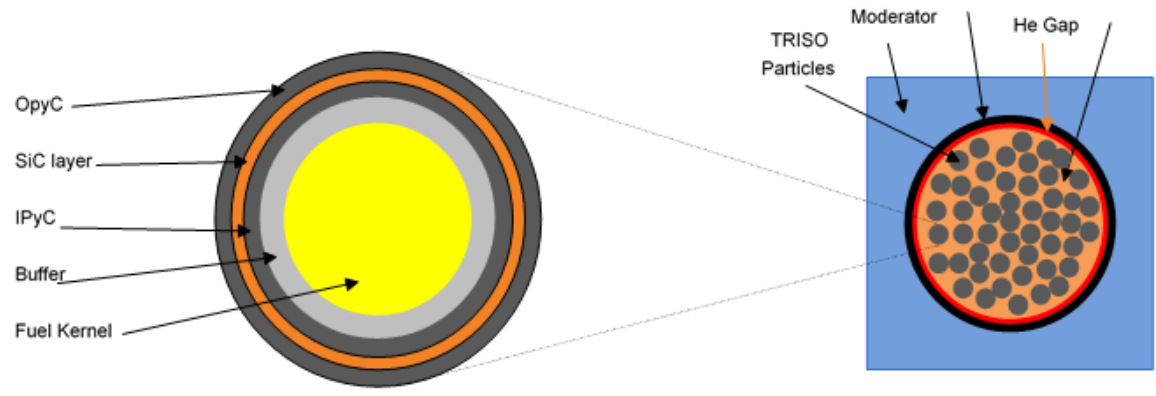

Figure 1. TRISO particle description

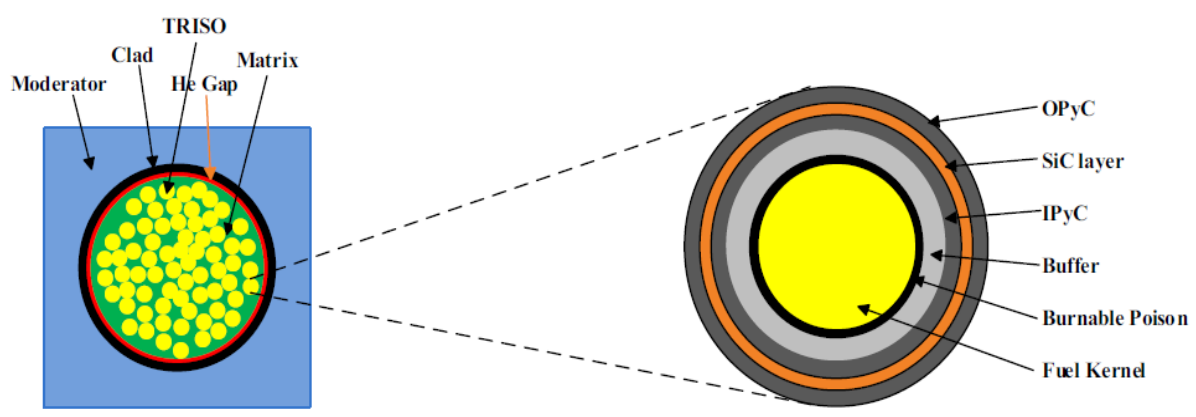

Figure 2. QUADRISO particle description

The specific parameters of TRISO particles are presented in the table. The parameters of the TRISO particle such as fuel kernel diameter and the thickness of various layers depends upon the survival of particles under the operational and accident conditions, these parameters are adjusted in such a way that the survival rate $99.5 \%$ at high temperatures such as $1600 \mathrm{C}$.

Table I. TRISO particle parameters.

\begin{tabular}{|l|c|}
\hline \multicolumn{1}{|c|}{ Parameter } & Value and Units \\
\hline Matrix SiC density & $3.18 \mathrm{~g} / \mathrm{cm}^{3}$ \\
\hline Fuel kernel & Uranium Carbide (UC) \\
\hline Kernel density & $12.95 \mathrm{~g} / \mathrm{cm}^{3}$ for UC \\
\hline Diameter of fuel kernel & $900 \mu \mathrm{m}$ \\
\hline Buffer density & $1.05 \mathrm{~g} / \mathrm{cm}^{3}$ \\
\hline Buffer thickness & $75 \mu \mathrm{m}$ \\
\hline IPyC Density/thickness & $1.9 \mathrm{~g} / \mathrm{cm}^{3} / 30 \mu \mathrm{m}$ \\
\hline
\end{tabular}




\begin{tabular}{|l|c|}
\hline SiC PV thickness & $35 \mu \mathrm{m}$ \\
\hline OPyC density/thickness & $1.1 \mathrm{~g} / \mathrm{cm}^{3} / 20 \mu \mathrm{m}$ \\
\hline
\end{tabular}

\section{APPENDIX B}

\section{Full Core Simulation Data}

The following table presents the full core simulation data.

Table I. Description of full core simulation data

\begin{tabular}{|c|c|c|}
\hline Parameters & Reference Fuel & FCM Fuel \\
\hline Fuel pellet radius & $0.3917 \mathrm{~cm}$ & $0.6461 \mathrm{~cm}$ \\
\hline Fuel material/matrix & $\mathrm{UO}_{2}$ & $\mathrm{UC} / \mathrm{SiC}$ \\
\hline Packing fraction & - & $35 \%$ \\
\hline Enrichment & $4.2 \%$ & $15.97 \%$ \\
\hline Heavy metal loading/FA & $486.748 \mathrm{~kg}$ & $128.298 \mathrm{~kg}$ \\
\hline HM $\%$ age of reference & $(100.0 \%)$ & $(26.35 \%)$ \\
\hline Initial fissile loading/FA & $20.43 \mathrm{~kg}$ & $20.43 \mathrm{~kg}$ \\
\hline Density of fuel & $10.40 \mathrm{~g} / \mathrm{cm}^{3}$ & $12.95 \mathrm{~g} / \mathrm{cm}^{3}$ \\
\hline Helium gap thickness & $0.0085 \mathrm{~cm}$ & $0.0085 \mathrm{~cm}$ \\
\hline Clad thickness & $0.069 \mathrm{~cm}$ & $0.057 \mathrm{~cm}$ \\
\hline No. of fuel rods & 312 & 160 \\
\hline Fuel rod radii (outer) & $0.4572 \mathrm{~cm}$ & $0.7116 \mathrm{~cm}$ \\
\hline No. of guide tubes & 19 & 9 \\
\hline Guide tube radii (outer/inner) & $0.630 \mathrm{~cm} / 0.550 \mathrm{~cm}$ & $\begin{array}{c}0.8613 \mathrm{~cm} / / 0.8043 \\
\mathrm{~cm}\end{array}$ \\
\hline Helium density & $0.00222 \mathrm{~g} / \mathrm{cm}^{3}$ & $0.00222 \mathrm{~g} / \mathrm{cm}^{3}$ \\
\hline Density of clad material (FeCrAl) & - & $7.25 \mathrm{~g} / \mathrm{cm}^{3}$ \\
\hline Density of moderator $\left(\mathrm{H}_{2} \mathrm{O}\right)$ & $0.72701 \mathrm{~g} / \mathrm{cm}^{3}$ & $0.72701 \mathrm{~g} / \mathrm{cm}^{3}$ \\
\hline Fuel temperature (ave) & $990.0 \mathrm{~K}$ & $950.0 \mathrm{~K}$ \\
\hline Cladding temperature (ave) & $600.0 \mathrm{~K}$ & $600.0 \mathrm{~K}$ \\
\hline Moderator temperature (ave) & $574.0 \mathrm{~K}$ & $574.0 \mathrm{~K}$ \\
\hline Pin pitch & $1.275 \mathrm{~cm}$ & $1.785 \mathrm{~cm}$ \\
\hline Fuel assembly pitch & $21.55 \mathrm{~cm}$ & $21.55 \mathrm{~cm}$ \\
\hline Fuel assembly height & $353.0 \mathrm{~cm}$ & $353.0 \mathrm{~cm}$ \\
\hline Fuel assembly power & $18.6 \mathrm{MW}$ & $18.6 \mathrm{MW}$ \\
\hline Number of Assemblies & 163 & 163 \\
\hline Total Thermal Power of Core & 3030 MWth & 3030 MWth \\
\hline RPV material & SS304 & SS304 \\
\hline Operating Pressure & $15.7 \mathrm{MPa}$ & $15.7 \mathrm{MPa}$ \\
\hline
\end{tabular}

